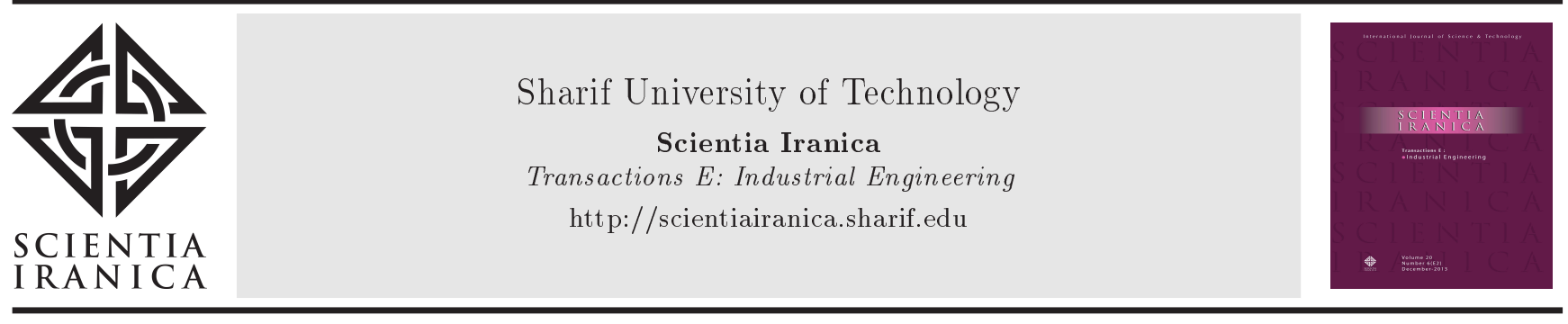

\title{
Stochastic optimization for the carrier selection problem in humanitarian relief
}

\author{
R. Ramezanian* and M. Ghorbani \\ Department of Industrial Engineering, K. N. Toosi University of Technology, Tehran, Iran.
}

Received 4 January 2020; received in revised form 9 August 2020; accepted 7 December 2020

KEYWORDS
Stochastic
optimization;
Carrier selection
problem;
Humanitarian relief;
Framework
agreement;
L-shaped algorithm.

\section{Introduction}

Nowadays, the number of natural and human-caused disasters threatening large populations across the world is on the rise. Since the disastrous 2004 tsunami in the Indian Ocean, awareness about the humanitarian supply chain has been considerably raised [1]. Generally, numerous natural disasters happen every year, the consequences of which are very catastrophic and unpredictable. Iran is one of the areas that is affected by the relatively high frequency of earthquakes (UNISDR, 2015). Altay and Green [2] estimated that the number of natural disasters would increase five

\footnotetext{
*. Corresponding author.

E-mail addresses: Ramezanian@kntu.ac.ir (R.

Ramezanian); Milad.Ghorbani@email.kntu.ac.ir ( $M$. Ghorbani)
}

doi: $10.24200 /$ sci.2020.55161.4100 times in the next 50 years. Habib et al. [3] demonstrated that the humanitarian supply chain and timely relief efforts had the potential of establishing one of the most significant global industries in the future. Effective planning of relief operations plays a critical role in saving lives and minimizing the property damages in disasters [4].

The necessity of the availability of carriers for transporting relief items to the affected areas in a disaster scenario is considered an important factor in terms of the humanitarian supply chain. Indeed, given the high demands for water, food, and sanitary equipment, the timely and prompt delivery of these goods to the affected areas becomes a major challenge to the managers and executives of the humanitarian relief. Any exact prediction of the time, location, and severity of the natural disaster is almost impossible. Demands for relief goods reach a dramatic peak in the face of a natural disaster and on-time delivery to the disaster areas plays a crucial role in humanitarian relief oper- 
ations. Therefore, the need for sufficient numbers of carriers to deliver the relief commodities to the disaster areas must be taken into consideration. Governmental and non-governmental humanitarian relief agencies can share the common sourcing and contracting approach in the supply chain to provide the carriers with quick access to deliver commodities to the disaster-inflicted areas. As a result, timely delivery of the relief items can be guaranteed by the availability of adequate carriers. In order to diminish the chance of facing lack of needed carriers prior to the disaster occurrence, contracts for renting carriers should be established with carrier suppliers. In this respect, the current study focuses on such supply contracts which are generally called longterm agreement or framework agreement. In this type of supply agreement, in accordance with the terms of a contract regarding price and quantity, the supplier agrees to reserve a number of carriers in times of need. Following the disaster occurrence, the organization requests carriers to transport relief commodities to the target areas. The objective pursued in here is to select enough carrier suppliers in the framework agreement considering the uncertainty in demands. In this regard, a new mathematical model was proposed to address the different dimensions of the decision-making process such as selecting the carrier suppliers, number of required carriers, and type of carriers.

The rest of the paper is organized as follows. In Section 2, a literature review of the subject is presented. In Sections 3 and 4, the problem definition and mathematical model are introduced. In Section 5, the problem-solving algorithm is developed. In Section 6, the case study and obtained results are given. In Section 7 , sensitivity analysis and numerical experiments are conducted; finally, in Section 8, the concluding remarks and future research suggestions are presented.

\section{Literature review}

Despite the importance of supplier selection in humanitarian relief, serious lack of related studies in this field is felt in the literature. However, in recent years, awareness about humanitarian relief has been on the rise. Our literature studies are divided into four categories including humanitarian relief, supplier selection, carrier selection, and contract models. Of note, gap analysis and major contributions of this research paper are discussed in this section.

\subsection{Humanitarian relief}

Barbarosoglu and Arda [5] proposed a two-stage stochastic programming model to plan on the transportation of relief goods to the disaster-stricken areas in the response phase. In order to explain the flow of commodity in an urban transportation network, they developed a multi-commodity multi-modal flow formulation. They considered uncertainty in the capacity, supply, and demand. Das and Hunaoka [6] developed a humanitarian relief inventory model with a uniformly distributed function in both demand and lead-time parameters. They also suggested different combinations of lead-time and demand scenarios to demonstrate the variability in their proposed model. Van Wassenhove [7] presented the idea to improve the performance of disaster logistics. He outlined some strategies for better preparedness as well as the agility, adaptability, and alignment of the supply chain while eliminating the complexities of supply chain management in a humanitarian setting. Alem et al. [8] developed a two-stage stochastic programming model to rapidly supply the demands of the affected areas. They attempted to improve demand fulfillment policy and presented conditional value-at-risk and semi-deviation for the expansion of their model. Perez-Rodriguez and Holguin-Versa [9] established an inventory-allocation-distribution model to minimize the social costs in the response phase for humanitarian logistics. They also suggested suitable designs for their solution approaches. Rezaei-Malek et al. [10] developed an integrated model to determine the best distribution and location-allocation plan and to attain the optimal ordering strategy for reviving the stored perishable goods in emergency preparedness situations. Ruan et al. [11] investigated the international shipping supply problem and introduced different carrier types, such as helicopters, and deciding factors, namely the helicopter time of travel, dispatch time, and delivery of different carriers, with the objective of responding to catastrophes of great magnitude. They also presented a model of routes optimization based on clustering in order to design international transportation routes. Moreno et al. [12] proposed a new model to optimize transportation, fleet, and location decisions to implement an effective response plan better and use supplies efficiently. In this regard, they considered uncertainty in demands, incoming supply, and accessibility of routes. Rodríguez-Espíndola et al. [13] presented a disaster preparedness system based on a combination of multi-objective optimization model and geographical information system to facilitate multi-organizational decision-making. In addition, they designed a multiobjective mixed-integer programming model associated with interoperability of involved agencies such as facility location, relief pre-positioning, and resource allocation. Tikani and Setak [14] proposed efficient solution algorithms to solve a time-critical reliable transportation problem emergency logistics management and attempted to minimize delays in delivering the relief items in disaster response operations.

\subsection{Supplier selection}

Aissaoui et al. [15] reviewed several already conducted 
researches that have addressed supplier selection decisions since the 1950s and found that price, delivery time, quality, and other important factors were utilized in the supply chain. A closer look at the previous studies in the supplier selection field reveals that some studies on the supplier selection in the specific field of the humanitarian supply chain have been carried out. Alfredsson and Verrijdt [16], Tagaras and Vlachos [17], and Lee et al. [18] studied relief supplier inventories and analyzed the cost of different forms and concerns associated with emergency stores and transportation in their problem. Hu et al. [19] developed a two-stage stochastic programming to integrate preparedness with response phases and procurement decisions, considering the humanitarian relief in the supplier selection problem. In their proposed model, they included three features namely return price, lead time discount, and equity. They also applied CVaR approach to measure the risks based on different confidence levels. Hazra and Mahadevan [20] considered the demand uncertainty, assumed that the buyer would reserve a capacity from one or more suppliers, and took into account the supplier selection based on the price of the reservation capacity. In their proposed model, the buyer's decision was quantitatively made based on the stipulated reserve capacity in the contract. $\mathrm{Li}$ and Zabinsky [21] presented a two-stage stochastic programming model and a chance-constrained programming model to ascertain the minimum quantity of order and minimum number of suppliers. Taking volume discounts into account, each supplier had a limited reserve capacity and demand was uncertain. Liao and Rittsche [22] developed a multi-objective model to measure the supplier flexibility while considering the uncertainty in timing and quantity of demand in supplier selection problem. Choi [23] developed a twostage supply selection problem, the first stage of which filtered the second-best suppliers, and the second phase selected the best suppliers from non-filtered suppliers at the first phase with a multi-objective randomized scheduling. Hammami et al. [24] presented a mixedinteger scenario-based stochastic programming in order to minimize the inventory, transportation, purchase price, and supplier management costs. Park and Lee [25] proposed a new hybrid model using data envelopment analysis (DEA) and analytical hierarchy process (AHP) for supplier selection.

\subsection{Carrier selection}

Lin and Yeh [26,27] proposed a logistics network based on network reliability criterion in the carrier selection problem. They also established a reliable network to successfully deliver the goods from a supplier to a consumer. In their paper, the definition allocated to carrier selection could select exactly one carrier on an exact route. Further, they developed a GA-based algorithm to ensure the carrier selection of maximum reliability and combine the minimal path with recursive sum of disjoint product. Meixell and Norbis [28] illustrated that logistic decisions concerning security in the supply chain would be made more effectively when considering decisions about the related supply chain processes, especially supplier and carrier selection. They proposed a decision process that featured a set of security rules as well as a multi-objective optimization model to accomplish this aim. The objective functions in their model were cost minimization, deviations from security goals, rejections, and late deliveries. Kolaee and Torabi [29] developed a multi-objective mathematical model to select the appropriate supplier and carrier and allocate orders of different products with different discount levels in each period to each supplier by suitable carriers. The objective functions in their model were cost minimization, delivery, number of defective items, and maximization of efficient suppliers. In this regard, they considered some criteria including cost, quality, delivery, resilience, social responsibility, and supplier profile to select the weight of each supplier by AHP. Their model was then solved through augmented $\varepsilon$-constraint method for determining Pareto-optimal solution. Davis-Sramek et al. [30] presented a carrier selection problem to manage social sustainability, environment, and transportation economics. They took into account three dimensions of sustainability discussed in the new empirical studies. They also employed experimental methods to experiment a priori assumption obtained from behavioral decision thesis logic.

\subsection{Contracts}

Pazirandeh [31] provided a literature review of the source strategy. He primarily attempted to provide a good prospect of research and decision-making for future research on humanitarian relief networks. Zhang and $\mathrm{Ma}$ [32] presented a mixed-integer programming model using single-source and multiple-source approaches on a supply network that included one producer and several suppliers with a discount policy. In their proposed model, the producer maximized its production level while the demand was uncertain. Balcik and Ak [33] presented a scenario-based model for uncertainty in demand. They considered setting up agreement with the supplier in the framework agreement based on a quantity flexibility where the discount amount increased according to the time windows and lead times. Nikkho et al. [34] presented a threeechelon supply chain containing a relief agency, a relief item supplier, and affected area in order to coordinate activities in quantity flexibility contract. The relief agencies and suppliers in their suggested contract were committed on a pre-specified amount for purchasing and supplying in the contract. Kuo et al. [35] proposed a service provider model to determine mutual resource 
allocation and pricing decisions. They considered two types of contracts with distinct service-level agreements and focused on the optimal contract design. Zhang et al. [36] developed a non-linear mathematical programming model that could determine the supplier selection in the framework agreement to establish a contract with selected suppliers. In their proposed contract, the relief agencies and suppliers were committed to purchasing and supplying the initial quantity. Shamsi et al. [37] introduced a special selecting contract for active prevention in order to provide the vaccine from the two main suppliers and supporters. They offered the contract to minimize social costs and buy the SIR epidemic model.

\subsection{Contribution of this paper}

A series of gaps were identified in the above-reviewed literature. For instance, the carrier selection problem did not take into account the contractual approach to the supply chain. Meanwhile, the whole problem was not addressed in the humanitarian supply chain. In this situation, lack of attention to the availability of adequate carriers when facing possible carrier shortage in a typical disaster situation is notable. Apart from supply goods, proper arrangement and availability of enough carriers are vital to rapid transfer of these relief items to the disaster-inflicted areas. In order to ensure on-time delivery of the vital commodities to the affected areas, the carrier selection problem along with establishing contracts regarding the carrier supplier approach was also taken into consideration, a point that has not been addressed yet.

The main contributions and novelties of this paper are summarized in the following:

- Managing the supplying of carriers in order to provide services and transfer/deliver relief commodities and equipment in times of disaster and serious disruption;

- Presentation of pre-disaster contracts, thus making framework agreements with the carrier suppliers considering the facilities, options, and capability of the suppliers and also their distance from the affected areas;

- Use of contracts for supplying carriers, thus ensuring the highest level of preparedness for humanitarian relief organizations in disaster situations. However, none of the aforementioned works considered contracts with carrier rentals;

- Application of two-stage stochastic programming in order to formulate the problem to consider both preand post-disaster decisions simultaneously for the carrier selection problem;

- Implementation of the proposed model and solution method in a real case study regarding an actual recent disaster in Iran;
- Consideration of the conventional policies such as minimum quantity commitment, extra reserve capacity, and different discounts in the model.

\section{Problem description}

Governments and relief agencies prefer adopting both outsourcing and sourcing policies to manage the disaster situations with high inventory costs, product spoilage, and shortage of carriers. Rapid and on-time responsibility is a key factor affecting the humanitarian relief in disaster situations. Due to the sudden surge in demands and need for rapid response to all demands, the likelihood of unsatisfaction as a consequence of shortages in commodities or the required carriers will arise. In spite of enough supplies, an efficient relief operation will not be possible in the case of the availability of carriers to transport goods to the disaster areas. Accordingly, providing enough carriers within a proper time is an important factor in the humanitarian relief. Therefore, considering the strategy of sourcing and contracting with carrier suppliers can be an effective approach in humanitarian relief operations. However, due to the inherent uncertain nature of disasters and lack of accurate and complete information on their magnitude and severity, the relief operation and intime response to demands become quite complicated. Therefore, the relief agencies should be ready to deliver relief goods to the disaster-inflicted areas on-time and must be able to solve the problem of shortage of required carriers through a proper carrier selection approach to establish the contract with carrier suppliers in the framework of a carrier rental agreement. In doing so, suppliers provide the relief organizations with enough carriers in case of disaster occurrence. In this regard, the main objective in this study is to select the carrier suppliers to establish a rental agreement in the pre-disaster stage and ensure the availability of enough carriers. To this end, a number of carrier suppliers were targeted, each with its own special features in terms of the initial carrier inventory, extra reserve capacity, distance from the disaster areas, discount percentage and price rise percentage in special situations, and general pricing policy.

A coverage distance was also taken into account to accelerate the transportation of commodities to the damaged areas. In other words, those suppliers are selected for the contract such that the total distance to the affected area is less than the coverage distance. As of the relief product process, the carriers are transported by the suppliers to the nearest warehouses and factories, where the relief supplies are stored, and then dispatched to the affected areas after loading the relief commodities.

Another problem to discuss is the allocation of each supplier to the disaster areas which can be done 
in a variety of ways. Assume that any supplier can be assigned to all of the disaster areas or multiple suppliers can be assigned to serve one or several disaster areas. The determining allocation criteria are the demands of the disaster areas and distance of these areas from the suppliers, which is determined by the demand and coverage distances, depending on how many suppliers and carriers of different types are responsive to the demands of the disaster area. Figure 1 illustrates the general concept of allocating carriers to different regions.

\section{Mathematical model}

In this section, a two-stage stochastic scenario-based programming model is considered for the carrier selection problem.

The sets, parameters, and variables of the problem can be defined below:

Sets:

$I \quad$ The set of candidate suppliers, $i \in I$

$J \quad$ The set of disaster areas, $j \in J$

$L \quad$ The set of types of carriers, $l \in L$

$S \quad$ The set of scenarios, $s \in S$

\section{Deterministic parameters:}

$e_{i l} \quad$ The number of $l$-type carriers stipulated in the contract with supplier $i$

$b_{i l} \quad$ The number of extra reservation capacity carriers of type $l$ stipulated in the contract with the supplier $i$

$v_{i l}^{\min } \quad$ Minimum commitment to renting the number of $l$-type carriers stipulated in the contract with supplier $i$

$B^{\text {min }} \quad$ The minimum number of authorized suppliers to select

$B^{\max } \quad$ The maximum number of authorized suppliers to select
$G_{l} \quad$ Non-commitment penalty for renting the minimum number of different types of $l$ carriers stipulated in the contract with the supplier $i$

$C V_{l} \quad$ The rental price offered for carriers of type $l$

$C F_{i} \quad$ The fixed cost of the contract with the supplier $i$

$C T_{l} \quad$ Unit transportation cost for carrier type $l$

$c c_{l} \quad$ The capacity of carrier type $l$

$R \quad$ Maximum coverage distance for each supplier

$H_{i j} \quad$ Shortest distance from supplier $i$ to affected area $j$

$\delta_{i} \quad$ The percentage of discount of supplier $i$

$\delta_{i}^{\prime} \quad$ The percentage of increase in the price of supplier $i$

\section{Stochastic parameters:}

$D_{j s} \quad$ Demand of disaster area $j$ to transport relief goods by the carriers under scenario $s$

$f r_{s} \quad$ Satisfying demand rate under scenario $s$

$\omega_{s} \quad$ Probability of occurrence of scenario $s$

\section{Preparedness stage variables:}

$y_{i} \quad$ Binary variable, if the supplier $i$ is selected 1; otherwise, 0

$x_{i j} \quad$ Binary variable, if supplier $i$ is selected to meet some of the demand of disaster area $j$; otherwise, 0

\section{Response stage variables:}

$q_{i j l s} \quad$ The number of carriers satisfying disaster area demand $j$ by supplier $i$ with $l$-type carrier under scenario $s$

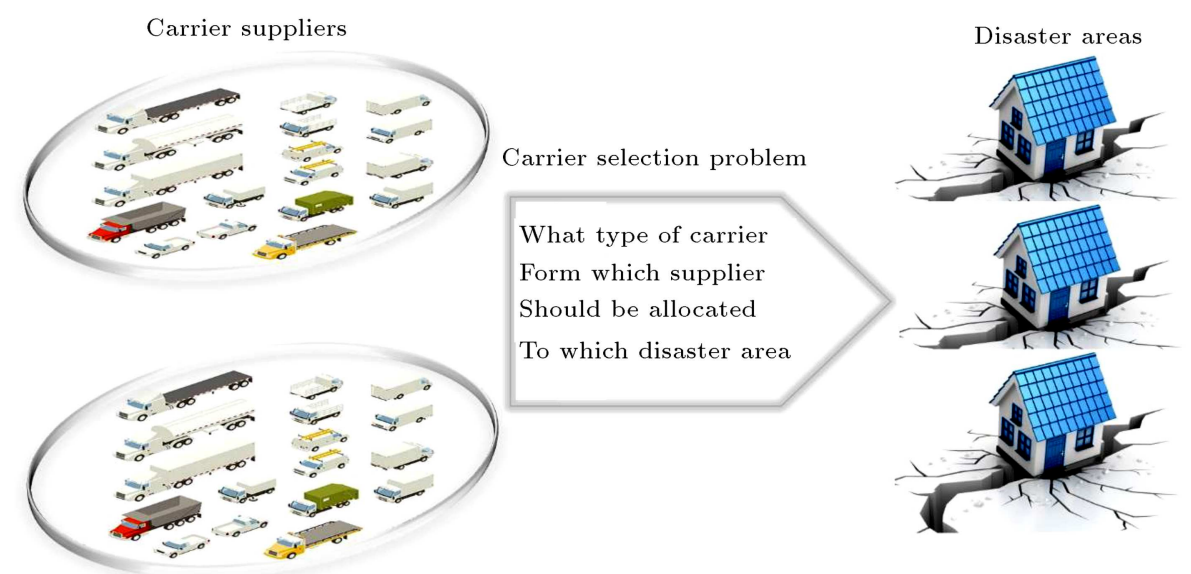

Figure 1. An overview of the selection and allocation of carriers to the disaster areas. 
$p_{i j l s} \quad$ The number of extra reserve carriers satisfying the extra demand of disaster area $j$ by supplier $i$ with $l$-type carriers under scenario $s$

$w_{i l s} \quad$ Non-commitment penalty for renting a minimum number of $l$-type carriers from a supplier $i$ under the scenario $s$

The following part is a general framework agreement on renting the carrier suppliers including:

- The number of carriers contracted with each supplier to provide a certain number of carriers to the relief agencies in a disaster situation is represented by $e_{i l}$;

- When selecting the supplier $i$, a minimum quantity of $v_{i l}^{\min }$ is considered for renting carriers of type $l$ from the supplier $i$. In this situation, a penalty must be paid if the required quantity is lower than the stipulated amount;

- An extra reserve capacity of $b_{i l}$ is stipulated for each supplier in the contract. If the supplier $i$ is asked more than $e_{i l}$, the extra reserve capacity is used and in this case, a specific percentage of the rental cost is added to the price;

- The percentage of discount is presented by $\delta_{i}$ which is different for each supplier. Each supplier determines the discount percentage when ordering equal to and less than $e_{i l}$ while $\delta_{i}^{\prime}$ is the price rise percentage when ordering more than the stipulated number in the contract $e_{i l}$;

- In case the supplier $i$ is selected and the number of carriers of type $l$ to be ordered from this supplier exceeds the stipulated number of contract $e_{i l}$, the specific stipulated percentage will be added to the rental price of the carrier. In addition, if the number of orders is equal to or less than $e_{i l}$, the percentage of the rental price is reduced;

- A coverage distance $R$ is considered while selecting suppliers so that organizations will make a contract with suppliers to cover this distance and the selected suppliers serve the areas within $R$;

Here, a mixed-integer linear programming model for a two-stage stochastic scenario-based carrier selection problem is presented as follows:

$$
\begin{aligned}
O B J^{\text {Stochastic }}= & \min \sum_{i \in I} C F_{i} \cdot y_{i}+\sum_{i \in I} \sum_{j \in J} \sum_{l \in L} \sum_{s \in S} \\
& \omega_{s} \cdot\left(1-\delta_{i}\right) \cdot C V_{l} \cdot q_{i j l s} \\
& +\sum_{i \in I} \sum_{j \in J} \sum_{l \in L} \sum_{s \in S} \omega_{s}\left(1+\delta_{i}^{\prime}\right)
\end{aligned}
$$

$$
\begin{gathered}
\quad+C V_{l} \cdot p_{i j l s} \sum_{i \in I} \sum_{j \in J} \sum_{l \in L} \sum_{s \in S} \omega_{s} \\
. C T_{l} \cdot H_{i j} \cdot\left(q_{i j l s}+p_{i j l s}\right) \\
+\sum_{i \in I} \sum_{l \in L} \sum_{s \in S} \omega_{s} \cdot G_{l} \cdot w_{i l s}, \\
\sum_{i \in I} y_{i} \leq B^{\max }, \\
\sum_{i \in I} y_{i} \geq B^{\min }, \\
y_{i} \geq x_{i j} \quad \forall i \in I, \quad j \in J, \\
H_{i j} \leq R+M\left(1-x_{i j}\right) \quad \forall i \in I, \quad j \in J, \\
q_{i j l s}+p_{i j l s} \leq M . x_{i j} \\
\forall i \in I, j \in J, l \in L, s \in S, \\
w_{i l s} \geq v_{i l}^{\min } . y_{i}-\sum_{j \in J} q_{i j l s}
\end{gathered}
$$$$
\forall i \in I, l \in L, s \in S
$$$$
\sum_{j \in J} q_{i j l s} \leq e_{i l} . y_{i} \quad \forall i \in I, l \in L, s \in S
$$$$
\sum_{j \in J} p_{i j l s} \leq b_{i l} . y_{i} \quad \forall i \in I, l \in L, s \in S
$$$$
\sum_{i \in I} \sum_{l \in L} c c_{l} \cdot q_{i j l s}+\sum_{i \in I} \sum_{l \in L} c c_{l} \cdot p_{i j l s} \geq D_{j s} \cdot f r_{s}
$$$$
\forall j \in J, s \in S \text {, }
$$

$$
\begin{aligned}
& y_{i}, x_{i j} \in\{0,1\} \quad \forall i \in I, j \in J, \\
& q_{i j l s}, p_{i j l s}, w_{i l s} \geq 0 \quad \forall i \in I, j \in J, l \in L, s \in S .
\end{aligned}
$$

The objective function (1) consists of five sections: The first part minimizes the fixed cost of contract with suppliers; the second part minimizes the cost of renting carriers from the contract $e_{i l}$; the third part minimizes the cost of requested carriers from the extra reservation capacity; the fourth part minimizes the transportation costs and finally, the fifth part minimizes the cost of a non-commitment penalty to rent a minimum number of carriers. Constraints (2) and (3) express the minimum and maximum numbers of authorized carrier suppliers to be selected. Constraint (4) ensures that if the supplier $i$ is not selected, the disaster area $j$ will not be served by supplier $i$. Constraint (5) guarantees that the authorized areas are provided by suppliers that are 
within the coverage distance. Constraint (6) makes sure that a carrier can be rented at a time when supplier $i$ is authorized to serve the critical area $j$. Constraint (7) guarantees that if the number of required carriers is less than the minimum stipulated number in the rental contract, a penalty cost will be paid. Constraint (8) ensures that the number of carriers submitted to the disaster areas from each supplier is equal to or less than the written number in the contract $e_{i l}$. Constraint (9) demonstrates the number of extra carriers needed after the crisis is limited by the reserve capacity. Constraint (10) guarantees that a specific percentage of demand is satisfied by the delivery carrier of the contract and that submitted from the extra reserve capacity. Constraints (11) and (12) determine the integrality of the variables.

\section{Solution methodology}

The proposed model is a scenario-based two-stage stochastic mixed-integer programming, often solved by solvers such as CPLEX in GAMS, which are only suitable to solve the problems of limited scales. The proposed model functions based on scenario(s) and due to the high number of scenarios, the problem size undergoes a dramatic increase. Therefore, with regard to the procedure of the L-shaped algorithm, decomposition of the problem into the master problem and sub-problems as well as decomposition of the subproblems into some small problems can be considered as appropriate approaches to solving such scenariobased two-stage problems on large scales. For the pre-disaster preparation stage and each scenario in the post-disaster response phase, an MILP model master problem and linear programming model of sub-problem were proposed, respectively, to reduce the problem size. The concept of the L-shaped algorithm is presented in the following.

\subsection{L-shaped algorithm}

Prior to introducing the master problem, the subproblem and feasibility check as well as the dual values obtained from the sub problem and feasibility check applied to make the feasibility cut and optimality cut should be introduced.

\subsubsection{Sub problem}

The objective function of the sub-problem is to minimize the carrier rental costs, transportation cost, and non-commitment penalties in all scenarios. The submodel can be developed by solving the master problem and obtaining $\left(x_{i j}, y_{i}\right)$ values. The mathematical model of the sub-problem is as follows:

$$
\min \pi_{s}=\sum_{i \in I} \sum_{j \in J} \sum_{l \in L} C V_{l} \cdot\left(1-\delta_{i}\right) \cdot q_{i j l s}
$$

$$
\begin{aligned}
&+\sum_{i \in I} \sum_{j \in J} \sum_{l \in L} C V_{l} \cdot\left(1+\delta_{i}^{\prime}\right) \cdot p_{i j l s} \\
&+\sum_{i \in I} \sum_{j \in J} \sum_{l \in L} H_{i j} \cdot C T_{l} \cdot\left(q_{i j l s}+p_{i j l s}\right) \\
&+\sum_{i \in I} \sum_{l \in L} G_{l} \cdot w_{i l s} \\
& w_{i l s} \geq v_{i l}^{\min } \hat{y}_{i}-\sum_{j \in J} q_{i j l s}
\end{aligned}
$$$$
\forall i \in I, l \in L, s \in S
$$$$
\sum_{j \in J} q_{i j l s} \leq e_{i l} . \hat{y}_{i} \quad \forall i \in I, l \in L, s \in S
$$$$
q_{i j l s}+p_{i j l s} \leq M . \hat{x}_{i j}
$$$$
\forall i \in I, j \in J, l \in L, s \in S
$$$$
\sum_{j \in J} p_{i j l s} \leq b_{i l} . \hat{y}_{i} \quad \forall i \in I, l \in L, s \in S
$$$$
\sum_{i \in I} \sum_{l \in L} c c_{l} \cdot q_{i j l s}+\sum_{i \in I} \sum_{l \in L} c c_{l} \cdot p_{i j l s} \geq D_{j s} \cdot f r_{s}
$$$$
\forall j \in J, s \in S
$$$$
q_{i j l s}, p_{i j l s}, w_{i l s} \geq 0
$$$$
\forall i \in I, j \in J, l \in L, s \in S
$$

Dual values of sub-problem are as follows:

$\alpha_{i l s}^{\nu} \quad$ Shadow price of Constraint (14) used in the optimal cut $v$

$\beta_{i l s}^{\nu} \quad$ Shadow price of Constraint (15) used in the optimal cut $v$

$\sigma_{i j l s}^{\nu} \quad$ Shadow price of Constraint (16) used in the optimal cut $v$

$\Gamma_{i l s}^{\nu} \quad$ Shadow price of Constraint (17) used in the optimal cut $v$

$\mu_{j s}^{\nu} \quad$ Shadow price of Constraint (18) used in the optimal cut $v$

\subsubsection{Feasibility check}

The feasibility check is now available in both L-shaped algorithm and sub-problem survey. The mathematical model of the feasibility check is presented below:

$$
\begin{aligned}
\min f_{s}= & \sum_{i \in I} \sum_{j \in J} \sum_{l \in L}\left(t_{i j l s}^{+}+t_{i j l s}^{-}\right) \\
& +\sum_{i \in I} \sum_{l \in L}\left(k_{i l s}^{+}+k_{i l s}^{-}+o_{i l s}^{+}+o_{i l s}^{-}\right.
\end{aligned}
$$




$$
\begin{array}{r}
\left.+u_{i l s}^{+}+u_{i l s}^{-}\right)+\sum_{j \in J}\left(g_{j s}^{+}+g_{j s}^{-}\right), \\
w_{i l s}+k_{i l s}^{+}-k_{i l s}^{-} \geq v_{i l}^{\min } \cdot \hat{y}_{i}-\sum_{j \in J} q_{i j l s}
\end{array}
$$$$
\forall i \in I, l \in L, s \in S
$$$$
\sum_{j \in J} q_{i j l s}+o_{i j l s}^{+}-o_{i j l s}^{-} \leq e_{i l} . \hat{y}_{i}
$$

$\forall i \in I, l \in L, s \in S$

$$
q_{i j l s}+p_{i j l s}+t_{i j l s}^{+}-t_{i j l s}^{-} \leq M . \hat{x}_{i j}
$$$$
\forall i \in I, j \in J, l \in L, s \in S \text {, }
$$

$\sum_{j \in J} p_{i j l s}+u_{i j l s}^{+}-u_{i j l s}^{-} \leq b_{i l} . \hat{y}_{i}$

$\forall i \in I, l \in L, s \in S$

$$
\begin{aligned}
& \sum_{i \in I} \sum_{l \in L} c c_{l} \cdot q_{i j l s}+\sum_{i \in I} \sum_{l \in L} c c_{l} \cdot p_{i j l s}+g_{j s}^{+} \\
& -g_{j s}^{-} \geq D_{j s} \cdot f r_{s} \quad \forall j \in J, s \in S, \\
& k_{i l s}^{+}, k_{i l s}^{-}, o_{i l s}^{+}, o_{i l s}^{-}, u_{i l s}^{+}, u_{i l s}^{-}, t_{i j l}^{+}, t_{i j l}^{-}, g_{j s}^{+}, g_{j s}^{-} \geq 0 \\
& \forall i \in I, j \in J, \quad l \in L, s \in S,
\end{aligned}
$$$$
q_{i j l s}, p_{i j l s}, w_{i l s} \geq 0
$$$$
\forall i \in I, j \in J, l \in L, s \in S \text {. }
$$

supplier within the coverage distance. The mathematical model of the master problem is given below:

$$
\begin{aligned}
& \min \sum_{i \in I} C F_{i} \cdot y_{i}+\theta, \\
& \sum_{i \in I} y_{i} \leq B^{\max } \\
& \sum_{i \in I} y_{i} \geq B^{\min }
\end{aligned}
$$

$$
\begin{aligned}
& y_{i} \geq x_{i j} \quad \forall i \in I, j \in J, \\
& \theta \geq \sum_{j} \sum_{s} \omega_{s} \cdot \mu_{j s}^{\nu} \cdot D_{j s} \cdot f r_{s} \\
& \quad+\sum_{i} \sum_{l} \sum_{s} \omega_{s}\left(\alpha_{i l s}^{v} \cdot v_{i l}^{\min } \cdot y_{i}+\beta_{i l s}^{v} \cdot e_{i l} \cdot y_{i}\right. \\
& \left.\quad+\Gamma_{i l s}^{v} \cdot b_{i l} \cdot y_{i}\right)+\sum_{i \in I} \sum_{j \in J} \sum_{l \in L} \sum_{s \in S} \omega_{s} \cdot M \cdot \sigma_{i j l s}^{v} \cdot x_{i j},
\end{aligned}
$$

$\sum_{j} \sum_{s} \psi_{j s}^{r} . D_{j s} \cdot f r_{s}$

Dual value of feasibility check are as follows:

$\rho_{i l s}^{r} \quad$ Shadow price of Constraint (21) used in the feasibility cut $r$

$\tau_{i l s}^{r} \quad$ Shadow price of Constraint (22) used in the feasibility cut $r$

$\eta_{i j l s}^{r} \quad$ Shadow price of Constraint (23) used in the feasibility cut $r$

$\gamma_{i l s}^{r} \quad$ Shadow price of Constraint (24) used in the feasibility cut $r$

$\psi_{j s}^{r} \quad$ Shadow price of Constraint (25) used in the feasibility cut $r$

\subsubsection{Master problem}

The objective function of the master problem is to minimize the fixed cost of the contract with the carrier supplier at the pre-disaster stage and approximate the lower bound of the costs at the post-disaster stage. Its variants include $y_{i}$ : the selection of the carrier suppliers and $x_{i j}$ : selection of the disaster areas serviced by the

$$
\begin{gathered}
+\sum_{i} \sum_{l} \sum_{s}\left(\rho_{i l s}^{r} \cdot v_{i l}^{\min } \cdot y_{i}+\tau_{i l s}^{r} \cdot e_{i l} . y_{i}\right. \\
\left.+\gamma_{i l s}^{r} . b_{i l} . y_{i}\right)+\sum_{i \in I} \sum_{j \in J} \sum_{l \in L} \sum_{s \in S} \eta_{i j l s}^{r} M . x_{i j} \leq 0, \\
y_{i}, x_{i j} \in\{0,1\} \quad \forall i \in I, j \in J .
\end{gathered}
$$

Constraint (32) includes the optimality cut constraints that are used to estimate an appropriate approximation, which defines its lower bound. Constraint (33) consists of feasibility check constraints. Then, the feasibility cut is added when the sub-problem has an infeasible solution.

Figure 2 illustrates a general framework of the L-shaped algorithm used for solving a scenario-based two-stage stochastic programming model.

\subsection{The value of $H N, W S, E E V, E V P I, V S S$}

This section elaborates the process of calculating the values of HN, WS, EEV, EVPI, and VSS. In this process, the expected value problem (EEV), Wait-and-See (WS), and Here-and-Now (HN) solutions are employed to measure the Expected Value of Perfect Information (EVPI) and Value of the Stochastic Solution (VSS) [38]. The EVPI is then utilized to estimate the highest value of credits about which the relief agencies desire to get absolute data in the future. On the contrary, VSS is employed to reveal the worth of solving and modeling stochastic programming [39]. The definitions of EEV, 


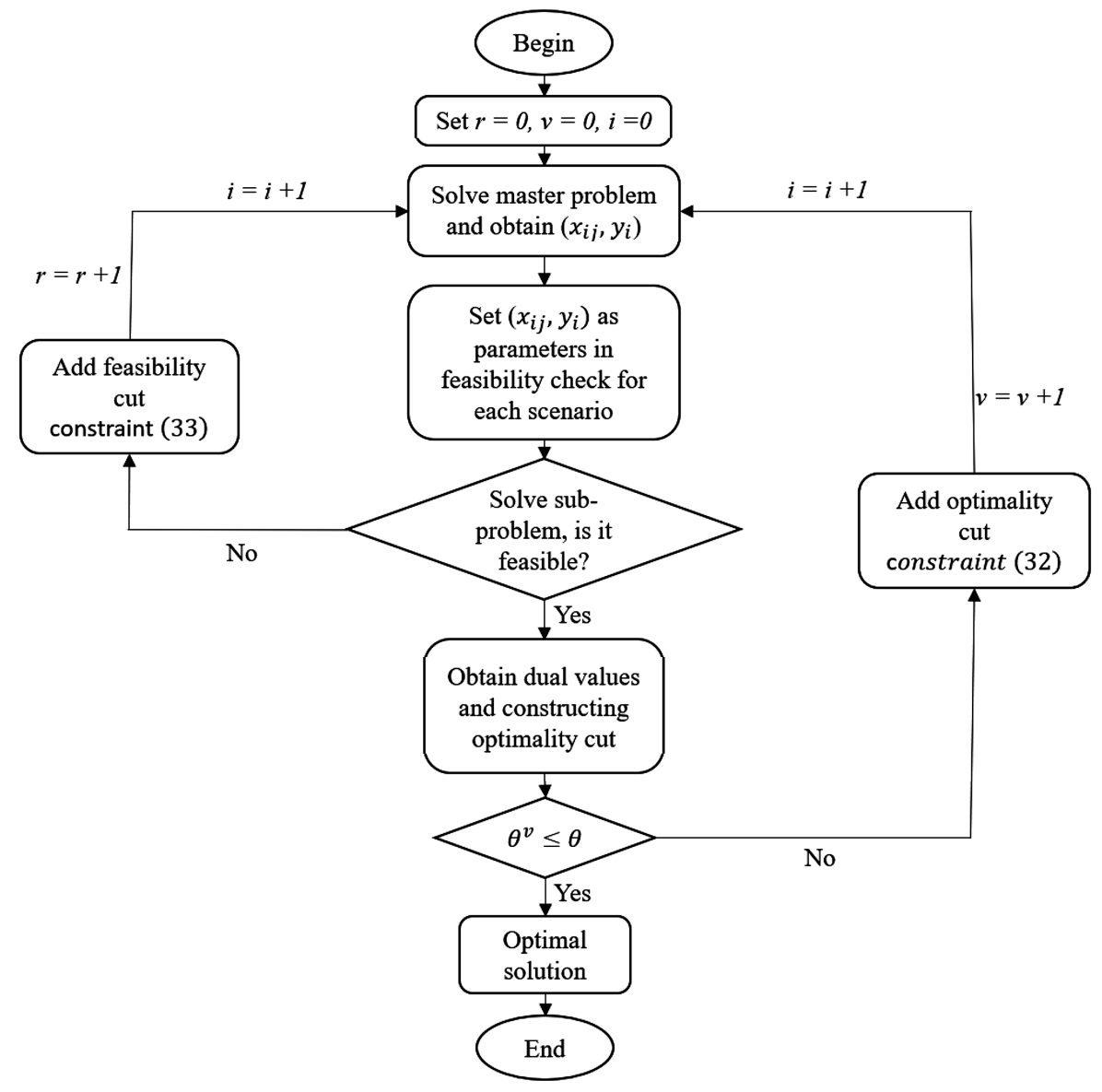

Figure 2. A solution perspective based on the L-shaped algorithm.

WS, and HN are illustrated as Constraints (35)(39) [40]. Here, $\bar{Y}(\bar{\xi})$ denotes the optimal solution related to the mean value of the stochastic data in the optimization problem. The VSS and EVPI are then calculated using Constraints (38) and (40):

$$
\begin{aligned}
& \bar{Y}(\bar{\xi})=\arg \min _{y \in Y}\left[c^{T} y+Q(y, \bar{\xi})\right], \\
& W S=E_{s}\left[\min _{y \in Y} c^{T} y+Q\left(y, \xi_{s}\right)\right], \\
& H N=\min _{y \in Y}\left\{c^{T} y+E_{s}\left[Q\left(y, \xi_{s}\right)\right]\right\}, \\
& E V P I=H N-W S, \\
& E E V=E_{s}\left[c^{T} \bar{Y}(\bar{\xi})+Q\left(\bar{Y}(\bar{\xi}), \xi_{s}\right)\right], \\
& V S S=E E V-H N .
\end{aligned}
$$

The deterministic model is proposed to obtain WS solution and $\bar{Y}(\bar{\xi})$, and the scenarios are invariable in the deterministic context.

$$
\begin{aligned}
& O B J^{\text {Deterministic }}= \\
& \min \sum_{i \in I} C F_{i} \cdot y_{i}+\sum_{i \in I} \sum_{j \in J} \sum_{l \in L}\left(1-\delta_{i}\right) \cdot C V_{l} \cdot q_{i j l} \\
& +\sum_{i \in I} \sum_{j \in J} \sum_{l \in L}\left(1+\delta_{i}^{\prime}\right) \cdot C V_{l} \cdot p_{i j l} \\
& \sum_{i \in I} \sum_{j \in J} \sum_{l \in L} C T_{l} \cdot H_{i j} \cdot\left(q_{i j l}+p_{i j l}\right) \\
& +\sum_{i \in I} \sum_{l \in L} G_{l} \cdot w_{i l} \\
& \sum_{i \in I} y_{i} \leq B^{\max } \\
& \sum_{i \in I} y_{i} \geq B^{\min } \\
& y_{i} \geq x_{i j} \quad \forall i \in I, j \in J, \\
& H_{i j} \leq R+M\left(1-x_{i j}\right) \quad \forall i \in I, j \in J, \\
& q_{i j l}+p_{i j l} \leq M . x_{i j} \quad \forall i \in I, j \in J, l \in L,
\end{aligned}
$$


$w_{i l} \geq v_{i l}^{\min } \cdot y_{i}-\sum_{j \in J} q_{i j l} \quad \forall i \in I, l \in L$,

$\sum_{j \in J} q_{i j l} \leq e_{i l} \cdot y_{i} \quad \forall i \in I, l \in L$,

$\sum_{j \in J} p_{i j l} \leq b_{i l} \cdot y_{i} \quad \forall i \in I, l \in L$,

$$
\begin{gathered}
\sum_{i \in I} \sum_{l \in L} c c_{l} \cdot q_{i j l}+\sum_{i \in I} \sum_{l \in L} c c_{l} \cdot p_{i j l} \geq D_{j} \cdot f r \\
\forall j \in J,
\end{gathered}
$$

$$
\begin{aligned}
& y_{i}, x_{i j} \in\{0,1\} \quad \forall i \in I, j \in J, \\
& q_{i j l}, p_{i j l}, w_{i l} \geq 0 \quad \forall i \in I, j \in J, l \in L .
\end{aligned}
$$

Eq. (53) presents the expected solution of the deterministic model which defines WS:

$$
W S=\sum_{s \in S} \omega_{s} . O B J_{s}^{\text {Deterministic }},
$$

s.t.: Constraints (42)-(52).

Eq. (54) presents the solution of the two-stage stochastic programming model based on scenarios.

$$
H N=O B J^{\text {Stochastic }}
$$

s.t.: Constraints (2)-(12).

Let $\bar{Y}(\bar{D})$ be the optimal solution related to the mean value of demands in the deterministic model, as shown in Constraint (55):

$$
\bar{Y}(\bar{D})=\arg \min _{y} O B J^{\text {Deterministic }}(Y, \bar{D}),
$$

s.t.:

$$
\sum_{i \in I} \sum_{l \in L} c c_{l} \cdot q_{i j l}+\sum_{i \in I} \sum_{l \in L} c c_{l} \cdot p_{i j l} \geq \sum_{s \in S} \omega_{s} . D_{j s} \cdot f r_{s} .
$$

Constraints (42)-(52).

The two-stage stochastic programming model based on scenarios is utilized and to calculate EEV solutions, the first stage decision variables $\bar{Y}(\bar{D})$ are applied as parameters, as shown in Constraint (56):

$$
\begin{aligned}
& E E V=O B J^{\text {Stochastic }}, \\
& \bar{Y}(\bar{\xi})=\arg \min _{y} O B J^{\text {Deterministic }}(Y, \bar{\xi}),
\end{aligned}
$$

Constraints (2)-(12).

\section{Case study}

The case study in this section is employed to show the applicability of the proposed model. A number of earthquake incidents happened in Iran in 2017. Although a majority of them were not destructive, one of these earthquakes occurred on a high magnitude scale of 7.3 on November 12, 2017 in Kermanshah in the western part of the country. The disaster caused financial and life losses. The data of the real case study was collected from the report obtained by Iran Red Crescent Society (IRCS), Statistical Center of Iran (SCI), National Disaster Management Organization of Iran (NDMOI), and also Japan International Cooperation Agency (JICA). The accumulated data from these sources contained a list of the demands in the affected areas, the location of suppliers, and occurrence probability of the earthquake scenarios. In addition, several other parameters were randomly generated to simulate the real-word situation using the information obtained by Tofighi et al. [41]. Figure 3 shows the study

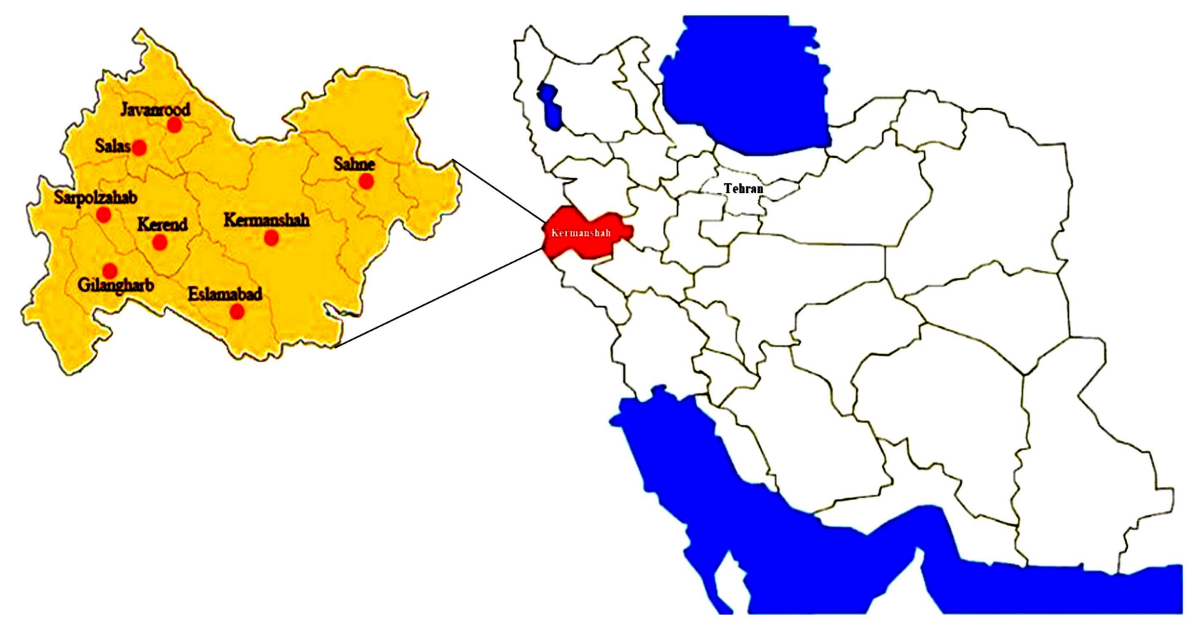

Figure 3. A picture of earthquake-stricken areas in Iran. 
areas. The current research primarily aimed to help the executives in the disaster management section to obtain appropriate decision-making strategies with a proper managerial insight for making the best decision in the disaster situation and providing the best possible relief operations.

Based on the information obtained from the above-mentioned sources, the numbers of people and areas affected by the earthquake are given in Table 1 .

Assume that each person needs 1.5 liters of drinking water each day. Given that each package contains six bottles with a capacity of 1.5 liters, the occupied space was calculated as 0.08 cubic meters. Each carrier has its own capacity with a trailer capacity of 81.25 cubic meters, a truck capacity of 26.4 cubic meters, and a pickup capacity of 4.6 cubic meters.

Rental carrier costs, transportation costs, and non-commitment penalty for the minimum number of rental contracts vary from carrier to carrier. However, the fixed contract costs, percent discount, and the price rise percentage resulting from using extra reserve capacity depend on the type of supplier. Of note, the satisfied demand rate varies from one scenario to another. Therefore, the probability of different scenarios and the rate of demand satisfaction can be determined based on the occurrence probability of different earthquake scales. Obviously, for a very highscale earthquake, demand satisfaction rate is lower than the lower-scale earthquake.
The magnitude of the earthquake in our study is 7.3 on the scale of Richter. The severity of the earthquake can be graded into three categories, which include earthquakes in the scale ranges of $(6,6.9)$, $(7,7.9)$, and $(8,8.9)$, respectively. Table 2 shows the damage caused by the severity of the earthquakes in disaster-stricken areas for each scenario. In this regard, earthquakes within the scale ranges of $(6,6.9)$, $(7,7.9)$, and $(8,8.9)$ contain scenarios $(8,12),(5,7)$, and $(1,4)$, respectively. As mentioned earlier, the studied earthquake was 7.3 Richter strong, thus falling into the second category. According to the information about the severity of the damage regarding this scale of the earthquake, other scenarios can be formed as well. Table 2 is presented below based on the abovementioned descriptions.

Coverage distance in the proposed model is one of the factors that can be beneficial to rapid transfer of relief commodities to the disaster areas. In addition to the earthquake-affected areas, a number of appropriate places should also be considered as the suppliers' sites. Figure 4 shows an overview of the earthquake-affected areas and location of suppliers. Table 3 also shows the distance between the suppliers and earthquake-affected areas.

GAMS software version 24.1.2, an optimization software used for general optimization problems, was used to obtain an optimal solution for the model. In this software, the CPLEX 12.5 solver was utilized in

Table 1. The population of each city and number of casualties.

\begin{tabular}{ccccccccc}
\hline City & Salas & Ghasreshirin & Kerend & Eslamabad & Javanroud & Sarpolezahab & Kermanshah & Sahne \\
\hline Population & 35219 & 23929 & 35987 & 140876 & 75169 & 85342 & 1083823 & 70757 \\
Victims & 15 & 28 & 14 & 22 & 3 & 316 & 25 & 3 \\
\hline
\end{tabular}

Table 2. Number of affected people in disaster areas in different scenarios.

\begin{tabular}{ccccccccc}
\hline Scenarios & Sarpolezahab & Ghasreshirin & Eslamabad & Salas & Kerend & Javanroud & Sahne & Kermanshah \\
\hline 1 & 81074 & 21536 & 98613 & 29936 & 28790 & 52618 & 42454 & 162573 \\
2 & 76808 & 20339 & 84525 & 28175 & 25191 & 45101 & 35379 & 108382 \\
3 & 72540 & 19143 & 70438 & 26414 & 23392 & 37584 & 28303 & 54191 \\
4 & 68274 & 17947 & 56350 & 24653 & 21592 & 30068 & 21228 & 27095 \\
5 & 59739 & 15554 & 42263 & 21131 & 17994 & 22551 & 14151 & 21676 \\
6 & 55472 & 14357 & 28175 & 19370 & 16194 & 18792 & 10614 & 16275 \\
$7^{*}$ & $\mathbf{5 1 2 0 5}$ & $\mathbf{1 3 1 6 1}$ & $\mathbf{1 4 0 8 7}$ & $\mathbf{1 7 6 0 9}$ & $\mathbf{1 4 3 9 5}$ & $\mathbf{1 5 0 3 4}$ & $\mathbf{7 5 7 6}$ & $\mathbf{1 0 8 4}$ \\
8 & 46938 & 11965 & 7044 & 15849 & 12595 & 11275 & 3538 & 0 \\
9 & 42671 & 10768 & 5635 & 14088 & 10796 & 7517 & 1415 & 0 \\
10 & 38404 & 9572 & 4226 & 12326 & 7197 & 3758 & 708 & 0 \\
11 & 34137 & 8375 & 2818 & 10566 & 5399 & 1503 & 0 & 0 \\
12 & 29870 & 7179 & 1409 & 8805 & 3599 & 0 & 0 & 0 \\
\hline
\end{tabular}

* 7.3 Richter earthquake which occurred in Kermanshah 
Table 3. The distance between the suppliers and earthquake areas.

\begin{tabular}{|c|c|c|c|c|c|c|c|c|}
\hline Suppliers & Sahne & Salas & Ghasreshirin & Kerend & Eslamabad & Javanroud & Sarpolezahab & Kermanshah \\
\hline Ilam & 236 & 228 & 148 & 150 & 114 & 214 & 160 & 171 \\
\hline Sanandaj & 190 & 184 & 312 & 235 & 199 & 133 & 282 & 136 \\
\hline Marivan & 321 & 213 & 304 & 296 & 260 & 159 & 343 & 267 \\
\hline Khorramabad & 248 & 333 & 332 & 256 & 220 & 319 & 302 & 277 \\
\hline Kuhdasht & 260 & 252 & 251 & 170 & 138 & 238 & 221 & 196 \\
\hline Nahavand & 80 & 279 & 325 & 249 & 213 & 230 & 296 & 147 \\
\hline Hamedan & 121 & 320 & 366 & 290 & 254 & 271 & 337 & 188 \\
\hline Malayer & 126 & 325 & 371 & 295 & 259 & 275 & 342 & 193 \\
\hline
\end{tabular}

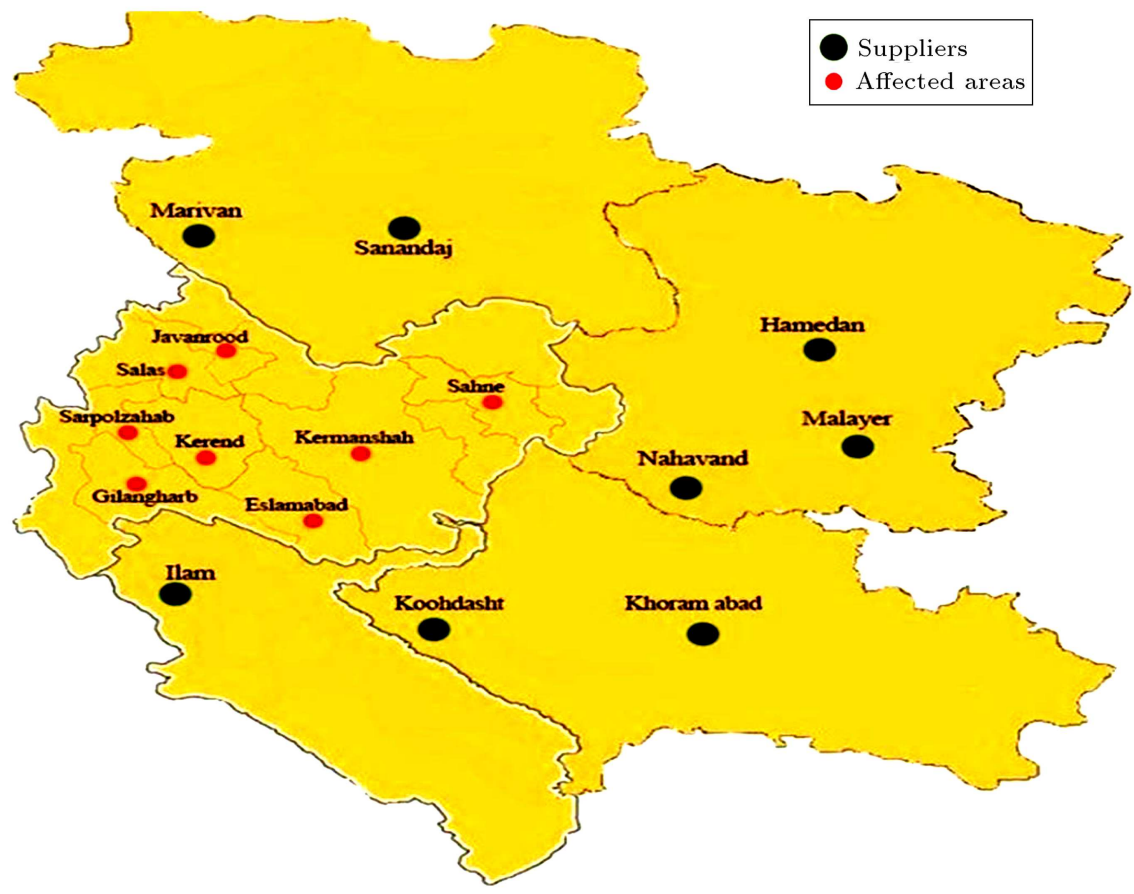

Figure 4. Suppliers' location and affected areas.

a computer equipped with Windows 10, Intel Core i5 processor, and $8 \mathrm{~GB}$ of RAM. The optimal solution was found within 7 seconds. Table 4 presents the conclusions of two types of approaches namely the base problem and base problem in case of satisfying all demands.

Considering that a fraction of demand in the base problem was outsourced, we managed to obtain the

Table 4. Results obtained from two types of approaches.

\begin{tabular}{lccc}
\multicolumn{1}{c}{ Result (unit cost: $€$ ) } & $\begin{array}{c}\text { Base } \\
\text { problem }\end{array}$ & $\begin{array}{c}\text { Satisfying } \\
\text { all demands }\end{array}$ & GAP \\
\hline $\begin{array}{l}\text { Total cost } \\
\begin{array}{l}\text { The cost of renting carriers from } \\
\text { the contract }\end{array}\end{array}$ & $184,014.021$ & $257,428.907$ & $39.90 \%$ \\
$\begin{array}{l}\text { The cost of requesting carriers from } \\
\text { the extra reservation capacity }\end{array}$ & $72,819.115$ & 87385.458 & $20.00 \%$ \\
$\begin{array}{l}\text { Non-commitment penalty to rent a } \\
\text { minimum number of carriers }\end{array}$ & $13,196.203$ & $23,600.378$ & $78.84 \%$ \\
$\begin{array}{l}\text { Transportation cost } \\
\text { Selected suppliers (number of selected suppliers) }\end{array}$ & $1,2,5,6(4)$ & $1,2,3,4,5,6,7(7)$ & $75.00 \%$ \\
\hline
\end{tabular}


number of the selected suppliers for establishing contract as four. In the case of satisfying all demands and assuming that all demands are outsourced, the number of the selected suppliers for establishing a contract increased to seven. In this situation, the contract and transportation costs would increase, compared to the base problem, due to the full outsourcing of demands, which, in turn, increases the number of the selected suppliers.

\section{Computational analysis}

\subsection{The result of $E V P I$ and $V S S$}

Table 5 shows the total costs of HN, WS, EVV, VSS, and EVPI. According to the results, the value of EVV is significantly higher than that of $\mathrm{HN}$, thus making the VSS value increase up to $1549.57249 €$. Given this amount, when the difference between these scenarios is significant in terms of demand and other cases depending on scenarios, modeling based on uncertainty can considerably reduce the expected costs. Furthermore, in the EVPI survey, when more information on the pre-disaster phase helps reduce the relief costs. The meaning of EVPI is that the imposed cost of $4089.58417 €$ results from the uncertainty in some scenario-dependent parameters, implying that relief organizations may spend up to $4089.58417 €$ to obtain information such as the time, location, severity, and the extent of the disaster.

According to the results and analysis of all the states, the managerial implications are discussed and the appropriate decision can be made by considering the financial, social, and environmental factors.

\subsection{The impact of variations in parameters}

The sensitivity analysis results of changes in the rental carrier costs and non-commitment penalties to the minimum quantity of contract within the variation range $(-50 \%,+50 \%)$ revealed that the rental costs had great impact on total costs. Since the main idea of the proposed model is to put more focus on the rental carrier costs, any cost changes will have a significant impact on the total cost. Figure 5 displays the sensitivity of the total cost to the variations of each cost.

Several factors affect the sensitivity analysis results such as the number of carrier supply contracts, parts of extra reserve capacity, and minimum amount of rents in the range of variations $(-50 \%, 50 \%)$. A review of the results indicates that variations in the number of contracts for the provision of carriers have a more important impact on the total cost. Of note, the problem aims to reach a contract where the best suppliers are selected among different suppliers. Figure 6 shows the sensitivity of the total cost to the variations in each of contract items.

For managers and decision-makers of the relief agencies, the prompt and timely response to the demands arising from the disaster-inflicted areas and the satisfaction of all demands without shortage are vital. In fact, our decision is conveyed to the managers to select the best type of contract, taking all aspects of the critical situation into account. As analyzed in the previous figures, among the most significant issues are the renting cost of a carrier and number of carrier contracts. Figure 7 shows the effect of the simultaneous changes in the cost of rental carriers and number of carrier contracts on the total cost.

The surveys and points outlined in the chart show the required flexibility under the contracts with regard to the price and number of carrier rentals. Accordingly, any simultaneous changes in these two factors are the same as the changes in the total cost in some points on the chart. Therefore, managers and decision-makers of the relief organizations as well as the providers reach contractual framework agreement in accordance with

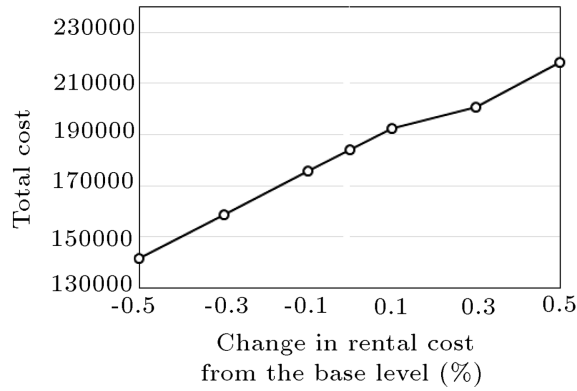

(a)

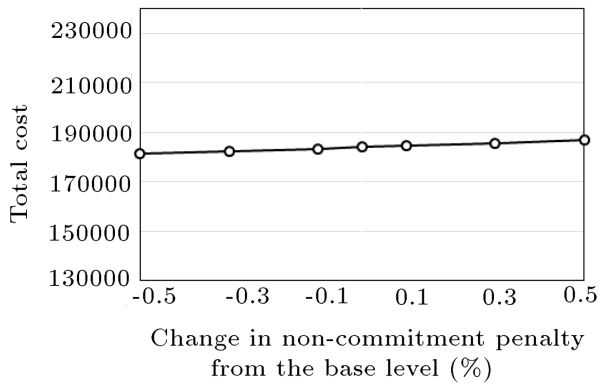

(b)

Figure 5. The sensitivity of costs to (a) carrier rental prices and (b) non-commitment penalty.

Table 5. Results obtained from HN, WS, EVV, EVPI, and VSS.

\begin{tabular}{cccccc}
\hline & HN & WS & EVPI & VSS & EVV \\
\hline Total cost & 184014.021 & 179924.4368 & 4089.58417 & 1549.57249 & 185563.5935 \\
\hline
\end{tabular}




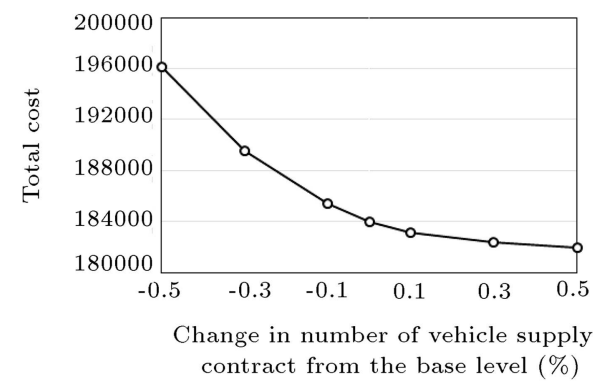

(a)

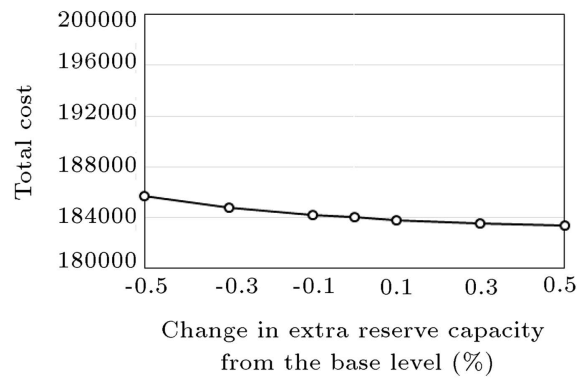

(b)

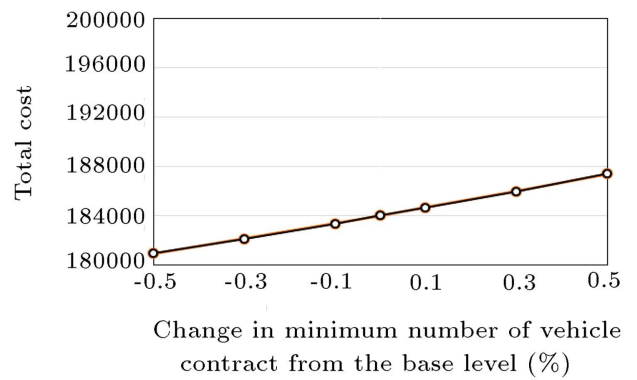

(c)

Figure 6. The sensitivity of cost to (a) number of carrier supply contracts, (b) extra reserve capacity, and (c) minimum number of rented carriers.

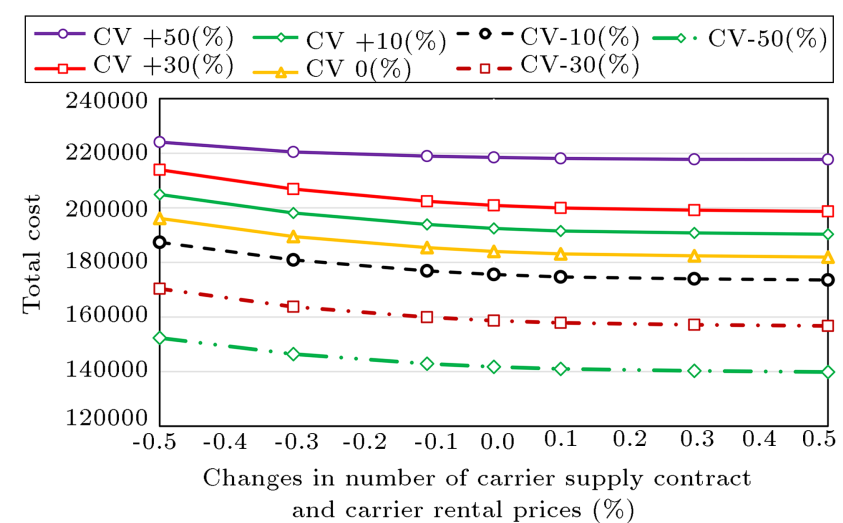

Figure 7. The sensitivity of cost to number of carrier supply contracts and carrier rental prices.

their specific circumstances and conditions.

Another significant issue in disaster situations is the coverage distance. According to the analysis results, reducing the coverage distance would result in fewer suppliers who deliver services to disaster areas. In this situation, more suppliers should be selected to cover the disaster area. Consequently, costs rise dramatically with an increase in the number of contracts. In addition, coverage distance aims to ensure a quick response and timely presence of the carriers in the disaster areas. Therefore, analysis of three factors namely coverage distance, time, and costs plays a significant role in decision-making. Figure 8 shows the changes in the time, costs, and coverage distance in relation with each other.

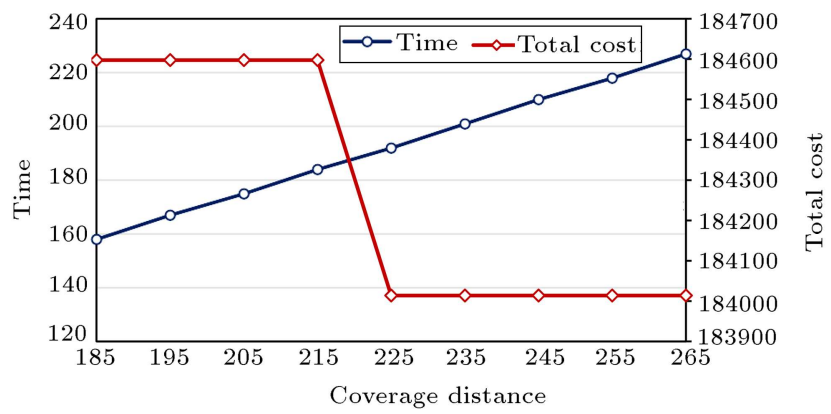

Figure 8. Changes in time, costs, and distance in relation with each other.

Relief agencies prefer to determine the shortest and most optimal possible coverage distance, considering both time and cost due to the prompt and timely response to the demand and lack of willingness of suppliers to serve the distant areas.

Demand-response capability plays a key role in disaster management, and relief agencies and managers try to thoroughly respond to the demands of disaster areas at the least possible time. A close study of the changes in the demand rate reveals that in order to increase the demand rate, contracts must be created with more suppliers, which will in turn add to the total cost. Figure 9 shows the sensitivity of the total cost to the increase in the demand satisfaction rate.

In this study, the demand-supply rate was set at $70 \%$, and if the demand-supply rate was to increase by $5 \%$, then the total cost would increase by $7 \%$. Therefore, managers and decision-makers could make 
Table 6. The parameters of the test instances.

\begin{tabular}{cccccl}
\hline Parameters & Value & Parameters & Value & Parameters & \multicolumn{1}{c}{ Value } \\
\hline$e_{i l}$ & $U(4,8)$ & $C F_{i}$ & $U(250,350)$ & $D_{j s}$ & $U(1000,10000)$ \\
$b_{i l}$ & $U(1,7)$ & $H_{i j}$ & $U(100,400)$ & $f r_{s}$ & $U(0.2,1)$ \\
$v_{i l}^{\text {min }}$ & $U(2,5)$ & $\delta_{i}$ & $U(0.05,0.2)$ & $\delta_{i}^{\prime}$ & $U(0.05,0.2)$ \\
\hline
\end{tabular}

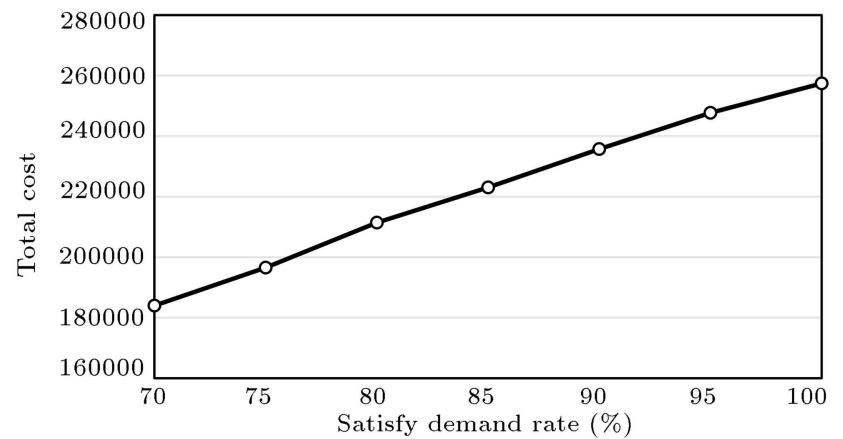

Figure 9. The sensitivity of the total cost to an increase in the demand satisfaction rate.

different decisions in terms of budget, time, and other limitations.

\subsection{Evaluation of solution method}

In this section, nine test instances with different sizes are presented to evaluate the performance of the Lshaped algorithm. As observed in Table 6, these test instances vary depending on the number of the carrier suppliers, affected areas, and scenarios. These test instances were randomly generated based on the uniformly distributed demand and different parameters given in Table 6 . Of note, the studies conducted by Alumur et al. [42], $\mathrm{Xu}$ and Nozick [43] were used to ensure the stability of the generated problem instances.

The L-shaped algorithm was coded in this study to solve the problem in GAMS software using CPLEX
12.5 solver. Table 7 shows the obtained results according to which the CPLEX solver is able to solve the problem instances of small and medium sizes; however, in cannot solve the problem instances of sizes larger than 2.5 hours. According to Table 7, upon increasing the size of the problem instances, the computation times will increase exponentially. From Sample 4 onwards, it is no longer possible to obtain the optimal solution using GAMS/CPLEX. As a result, the Lshaped algorithm is used to tackle the problem with larger instances. While examining the performance of the L-shaped algorithm, it was found that this algorithm not only could solve the problem in the small- and medium-size instances, but also exhibited high performance in the case of large-size problems.

The last column heading "GAP\%" shows the relative difference between the objective function values obtained by CPLEX and L-shaped algorithm which is calculated as follows:

$$
G A P \%=100 *
$$

(CPLE $X_{\text {objective value }}-L-$ shaped $\left._{\text {objective value }}\right) /$

$$
L-\text { shaped }_{\text {objective value }}
$$

\section{Conclusion and future studies}

The present study highlights the significance of the carrier selection problem and considers the carrier rental

\begin{tabular}{|c|c|c|c|c|c|c|c|c|}
\hline \multirow{2}{*}{$\begin{array}{c}\text { Size } \\
|i| \times|j| \times|l| \times|s|\end{array}$} & \multicolumn{5}{|c|}{ L-Shaped } & \multicolumn{2}{|c|}{ CPLEX } & \multirow[b]{2}{*}{ GAP (\%) } \\
\hline & $\begin{array}{c}\text { Runtime } \\
\text { (sec) }\end{array}$ & Iter. & $\begin{array}{c}\text { Feas. } \\
\text { cut }\end{array}$ & $\begin{array}{c}\text { Opt. } \\
\text { cut }\end{array}$ & $\begin{array}{l}\text { Obj. } \\
\text { value }\end{array}$ & $\begin{array}{c}\text { Runtime } \\
\text { (sec) }\end{array}$ & $\begin{array}{c}\text { Obj. } \\
\text { value }\end{array}$ & \\
\hline$|20| \times|20| \times|3| \times|36|$ & 68 & 94 & 147 & 254 & 705,393 & 174 & 705,393 & $<1$ \\
\hline$|20| \times|30| \times|3| \times|36|$ & 196 & 152 & 338 & 684 & $1,199,168$ & 365 & $1,201,083$ & $<1$ \\
\hline$|30| \times|30| \times|3| \times|36|$ & 271 & 148 & 411 & 822 & $1,272,917$ & 1,246 & $1,276,368$ & $<1$ \\
\hline$|30| \times|30| \times|3| \times|72|$ & 434 & 161 & 429 & 865 & $1,953,291$ & 2,470 & $1,958,463$ & $<1$ \\
\hline$|30| \times|40| \times|3| \times|72|$ & 592 & 167 & 271 & 1124 & $4,206,087$ & 4,895 & $4,285,140$ & 1.88 \\
\hline$|40| \times|40| \times|3| \times|72|$ & 969 & 218 & 547 & 1097 & $3,988,796$ & 7,163 & $4,117,063$ & 3.22 \\
\hline$|40| \times|40| \times|3| \times|144|$ & 1432 & 193 & 702 & 1310 & $4,410,153$ & 8,034 & $4,698,929$ & 6.55 \\
\hline$|40| \times|50| \times|3| \times|144|$ & 1680 & 209 & 664 & 1459 & $8,969,567$ & $>9,000$ & $9,974,472$ & 11.20 \\
\hline$|50| \times|50| \times|3| \times|144|$ & 2349 & 247 & 613 & 1757 & $9,799,252$ & $>9,000$ & $10,961,051$ & 11.86 \\
\hline$|50| \times|50| \times|3| \times|432|$ & 5193 & 349 & 847 & 1746 & $18,365,422$ & $>9,000$ & $21,974,962$ & 19.65 \\
\hline$|50| \times|50| \times|3| \times|1296|$ & $>9,000$ & 527 & 1004 & 1814 & $22,011,326$ & $>9,000$ & $26,756,967$ & 21.56 \\
\hline
\end{tabular}

Table 7. Performance evaluation of the L-Shaped algorithm.

Note: Iter.: Iteration; Feas.: Feasibility; Opt.: Optimality; and Obj.: Objective. 
contracts in humanitarian relief. Each supplier was selected based on several criteria such as the ability to provide carriers, discount percentage in the contract for renting the carriers, the price rise percentage for extra reserve capacity, and geographical location. Regarding the analysis of the supplier contract terms, the most significant impact on the evaluation of demand and total cost is related to the cost and the number of carrier rentals from the suppliers, and simultaneous analysis of these factors provides a flexible and appropriate insight for establishing the optimal agreement with the suppliers while considering financial, social and environmental factors. Based on the geographical location and the coverage distance analysis in the managerial insights section and considering the importance of acceleration in relief operations, cost, time, and distance factors were analyzed and appropriate results were obtained. A scenario-based two-stage stochastic programming model was developed for handling the uncertainty of demand, taking the probability for each scenario into account. To solve the stochastic model, the L-shaped algorithm was applied and WS and EVV approaches were used to demonstrate the efficiency of the presented algorithm. Furthermore, to analyze the effects of contractual decisions on carrier selection, a number of analyses were conducted and the results demonstrated significant impact on the cost and the number of carrier rentals. A real case study was studied and investigated in order to validate the viability of the proposed model. Some managerial insights were provided for decision-makers in relief agencies and governments. In this study, several topics were presented that could be useful for future research: (1) Integrating various supply sources into the framework of a contract. Considering various options for providing resources, including donations and global and local markets, which can be an effective approach in terms of making contracts regarding the humanitarian relief. (2) Uncertainty about the funds available in the post-disaster situation. The quantity of items for buying from a supplier in the framework of a contract or from other sources may depend on available financial resources in the post-disaster situation, which can be considered as a scenario-based approach to uncertainty in the amount of available funds. (3) Supplier reliability. The framework agreement put forward in this paper implies that the supplier ensures that adequate quantities of carriers are provided for humanitarian relief organizations under disaster conditions. However, in some cases, the supplier may not possess the ability to provide such sufficient means of transportation, in which case many damaging ramifications could follow. Therefore, it is possible to present a suitable model using the reliability approach for the supplier performance. (4) The probability of various disasters occurring consecutively and in short intervals. A scenario-based approach can be proposed to combine multiple and continuous types of disasters, and the simulation approach can be used to provide a suitable model for dealing with such circumstances.

\section{References}

1. Athukorala, P.C. and Resosudarmo, B.P. "The Indian Ocean tsunami: Economic impact, disaster management, and lessons", Asian Economic Papers, 4(1), pp. 1-39 (2005).

2. Altay, N. and Green, W.G.I. "OR/MS research in disaster operations management", European Journal of Operational Research, 175, p. 475-493 (2006).

3. Habib, M.S., Lee, Y.H., and Memon, M.S. "Mathematical models in humanitarian supply chain management: A systematic literature review", Mathematical Problems in Engineering, 20(1), pp. 1-20 (2016).

4. Zheng, Y.J., Chen, S.Y., and Ling, H.F. "Evolutionary optimization for disaster relief operations: A survey", Applied Soft Computing, 27, pp. 553-566 (2015).

5. Barbarosoglu, G. and Arda, Y. "A two-stage stochastic programming framework for transportation planning in disaster response", Journal of the Operational Research Society, 55(1), pp. 43-53 (2004).

6. Das, R. and Hanaoka, S. "Relief inventory modelling with stochastic lead-time and demand", European Journal of Operational Research, 235(3), pp. 616-623 (2014).

7. Van Wassenhove, L.N. "Humanitarian aid logistics: supply chain management in high gear", Journal of the Operational Research Society, 57(5), pp. 475-489 (2006).

8. Alem, D., Clark, A., and Moreno, A. "Stochastic network models for logistics planning in disaster relief", European Journal of Operational Research, 255(1), pp. 187-206 (2016).

9. Perez-Rodriguez, N., and Holguin-Veras, J. "Inventory -allocation distri-bution models for post-disaster humanitarian logistics with explicit consideration of deprivation costs", Transportation Science, 50(4), pp. 1261-1285 (2015).

10. Rezaei-Malek, M., Tavakkoli-Moghaddam, R., Zahiri, B., et al. "An interactive approach for designing a robust disaster relief logistics network with perishable commodities", Computer and Industrial Engineering, 94, pp. 201-215 (2016).

11. Ruan, J.H., Wang, X.P., Chan, F.T.S., et al. "Optimizing the intermodal transportation of emergency medical supplies using balanced fuzzy clustering", International Journal of Production Research, 54(14), pp. 4368-4386 (2016).

12. Moreno, A., Alem, D., Ferreira, D., et al. "An effective two-stage stochastic multi-trip location-transportation model with social concerns in relief supply chains", European Journal of Operational Research, 269(3), pp. 1050-1071 (2018). 
13. Rodríguez-Espíndola, O., Albores, P., and Brewster, C. "Disaster preparedness in humanitarian logistics: a collaborative approach for resource management in floods", European Journal of Operational Research, 264, pp. 978-993 (2018).

14. Tikani, H. and Setak, M. "Efficient solution algorithms for a time-critical reliable transportation problem in multigraph networks with FIFO property", Applied Soft Computing, 74, pp. 504-528 (2019).

15. Aissaoui, N., Haouari, M., and Hassini. E. "Supplier selection and order lot sizing modeling: A review", Computer and Industrial Engineering, 34(12), pp. 3516-3540 (2007).

16. Alfredsson, P. and Verrijdt, J. "Modeling emergency supply flexibility in a two-echelon inventory system", Management Science, 45(10), pp. 1416-1431 (1999).

17. Tagaras, G. and Vlachos, D. "Effectiveness of stock transshipment under various demand distributions and non-negligible transshipment times", Production and Operations Management, 2, pp. 183-198 (2002).

18. Lee, Y., Jung, J., and Jeon, Y. "An effective lateral transshipment policy to improve service level in the supply chain", International Journal of Production Economics, 106(1), pp. 115-126 (2007).

19. Hu, S.L., Han, C.F., and Meng, L.P. "Stochastic optimization for joint decision making of inventory and procurement in humanitarian relief", Computer and Industrial Engineering, 111, pp. 39-49 (2017).

20. Hazra, J. and Mahadevan, B. "A procurement model using capacity reservation", European Journal of Operational Research, 193, pp. 303-316 (2009).

21. Li, L. and Zabinsky, Z. "Incorporating uncertainty into a supplier selection problem", International Journal of Production Economics, 134, pp. 344-356 (2011).

22. Liao, Z. and Rittsche, J. "A multi-objective supplier selection model under stochastic demand conditions", International Journal of Production Economies, 105, pp. 150-159 (2007).

23. Choi, T.M. "Optimal apparel supplier selection with forecast updates under carbon emission taxation scheme", Computer and Operations Research, 40(11), pp. 2646-2655 (2013).

24. Hammami, R., Temponi, C., and Fein, Y. "A scenariobased stochastic model for supplier global context with multiple buyers, currency fluctuation uncertainties, and price discounts", European Journal of Operational Research, 233(1), pp. 159-170 (2014).

25. Park, S.C. and Lee, J.H. "Supplier selection and stepwise benchmarking: a new hybrid model using DEA and AHP based on cluster analysis", Journal of the Operational Research Society, 69(3), pp. 1-20 (2018).

26. Lin, Y-K. and Yeh, C-T. "Optimal carrier selection based on network reliability criterion for stochastic logistics networks", International Journal of Production Economics, 128, pp. 510-517 (2010).

27. Lin, Y-K. and Yeh, Ch-T. "Determine the optimal carrier selection for a logistics network based on multicommodity reliability criterion", International Journal of Systems Science, 44, pp. 949-964 (2013).

28. Meixell, M.J. and Norbis, M. "Integrating carrier selection with supplier selection decisions to improve supply chain security", International Transaction in Operational Research, 19, pp. 711-732 (2012).

29. Kolaee, M.H. and Torabi, S.A. "Supplier and carrier selection and order allocation by considering disruption with AHP and multi-objective mathematical programming", International Journal of Supply and Operations Management, 4, pp. 359-369 (2017).

30. Davis-Sramek, B., Thomas, R.W., and Fugate, B.S. "Integrating behavioral decision theory and sustainable supply chain management: Prioritizing economic, environmental, and social dimensions in carrier selection", Journal of Business Logistics, 39, pp. 87-100 (2018).

31. Pazirandeh, A. "Sourcing in global health supply chains for developing countries", International Journal of Physical Distribution Logistics Management, 41(4), pp. 364-384 (2011).

32. Zhang, G. and Ma, L. "Optimal acquisition policy with quantity discounts and uncertain demands", International Journal of Production Research, 47(9), pp. 2409-2425 (2009).

33. Balcik, B. and Ak, D. "Supplier selection for framework agreement in humanitarian relief", Production and Operation Management, 23(6), pp. 1028-1041 (2014).

34. Nikkho, F., Bozorg-Amiri, A., and Heydari, J. "Coordination of relief items procurement in humanitarian logostic based on quantity flexibility contract", International Journal of Disaster Risk Reduction, 31, pp. 331-340 (2018).

35. Kuo, C.W., Huang, K.L., and Yang, C.L. "Optimal contract design for cloud computing service with resource service guarantee", Journal of the Operational Research Society, 68(9), pp. 1030-1044 (2017).

36. Zhang, J-H., Sun, X-Q., Zhu, R., et al. "Solving an emergency rescue materials problem under the joint reserves mode of government and framework agreement suppliers", PLoS ONE, 12(10), p. e0186747 (2017).

37. Shamsi, G.N., Torabi, S.A., and Shakouri, G.H. "An option contract for vaccine procurement using the SIR epidemic model", European Journal of Operational Research, 267(3), pp. 1122-1140 (2018).

38. Birge, J.R. and Louveaux, F., Introduction to Stochastic Programing, New York: Springer (1997).

39. Chaharsooghi, S.K., Honarvar, M., Modarres, M., et al. "Developing a two stage-stochastic programming 
model of the price and lead-time decision problem in the multi-class make-to-order firm", Computers and Industrial Engineering, 61(4), pp. 1086-1097 (2011).

40. Noyan, N. "Risk-averse two-stage stochastic programming with an application to disaster management", Computers and Operations Research, 39(3), pp. 541559 (2012).

41. Tofighi, S., Torabi, S.A., and Mansouri, S.A. "Humanitarian logistics network design under mixed uncertainty", European Journal of Operational Research, 250(1), pp. 239-250 (2016).

42. Alumur, S.A., Nickel, S., Saldanha-da-Gama, F., et al. "Multi-period reverse logistics network design", European Journal of Operational Research, 220(1), pp. 67-78 (2012).

43. Xu, N. and Nozick, L. "Modeling supplier selection and the use of option contracts for global supply chain design", Computers and Operations Research, 36(10) pp. 2786-2800 (2009).

\section{Biographies}

Reza Ramezanian is an Associate Professor of Industrial Engineering at K. N. Toosi University of Technology. He received $\mathrm{BSc}, \mathrm{MSc}$, and $\mathrm{PhD}$ degrees from Iran University of Science and Technology, Tehran, Iran. His research interests include operations research, supply chain management, transportation scheduling, production planning and scheduling, and stochastic optimization.

Milad Ghorbani received his MSc degree in Industrial Engineering form K. N. Toosi University of Technology, Iran. He is currently a $\mathrm{PhD}$ candidate in Industrial Engineering at Laval University, Canada. His main research area includes operations research, stochastic programming, supply chain and logistics, reliability, maintenance planning, and exact algorithms. 